(1)

\title{
Effects of running wheel training on adult obese rats programmed by maternal prolactin inhibition
}

\author{
G Boaventura, G Casimiro-Lopes, C C Pazos-Moura', E Oliveira, \\ P C Lisboa and E G Moura
}

Correspondence should be addressed

Departamento de Ciências Fisiológicas, $5^{\circ}$ Andar, Instituto de Biologia Roberto Alcantara Gomes, Universidade do Estado do Rio de Janeiro, Avenida 28 de Setembro, 87, Rio de Janeiro 20551-030, Brazil

${ }^{1}$ Instituto de Biofisica Carlos Chagas Filho, Universidade Federal do Rio de Janeiro, Rio de Janeiro, Brazil

to P C Lisboa

Email

pclisboa@uerj.br

\begin{abstract}
The inhibition of maternal prolactin production in late lactation leads to metabolic

syndrome and hypothyroidism in adult offspring. Physical training is a therapeutic strategy that could prevent or reverse this condition. We evaluated the effects of a short-duration low-intensity running wheel training program on the metabolic and hormonal alterations in rats. Lactating Wistar rats were treated with bromocriptine (Bro, $1 \mathrm{mg}$ twice a day) or saline on days 19,20, and 21 of lactation, and the training of offspring began at 35 days of age. Offspring were divided into sedentary and trained controls (C-Sed and C-Ex) and sedentary and trained Bro-treated rats (Bro-Sed and Bro-Ex). Chronic exercise delayed the onset of weight gain in Bro-Ex offspring, and the food intake did not change during the experimental period. At 180 days, visceral fat mass was higher $(+46 \%)$ in the Bro-Sed offspring than in C-Sed and Bro-Ex rats. As expected, running capacity was higher in trained animals. Most parameters observed in the Bro-Sed offspring were consistent with hypothyroidism and metabolic syndrome and were reversed in the Bro-Ex group. Chronic exercise did not influence the muscle glycogen in the C-Ex group; however, liver glycogen was higher $(+30 \%)$ in C-Ex group and was unchanged in both Bro offspring groups. Bro-Ex animals had higher plasma lactate dehydrogenase levels, indicating skeletal muscle damage and intolerance of the training program. Low-intensity chronic training is able to normalize many clinical aspects in Bro animals; however, these animals might have had a lower threshold for exercise adaptation than the control rats.
\end{abstract}

Key Words

\section{Introduction}

Obesity is a health problem that is increasing at an astounding rate around the world. This condition is directly related to many health problems and results in a higher risk of other chronic non-communicable diseases and death (Beaglehole \& Yach 2003). Some studies point to the quantity of visceral fat and its particular inflammatory profile to explain the adverse metabolic effects of obesity (Bosello \& Zamboni 2000, Masuzaki et al. 2001).

Chronic exercise (physical training) is an interesting therapeutic strategy to counter the obesity epidemic. The American College of Sports Medicine recommends that most adults engage in moderate-intensity cardiorespiratory

Published by Bioscientifica Ltd 
exercise for a minimum of $30 \mathrm{~min}, 5$ days/week (Garber $\mathrm{etal}$. 2011). Studies showed that rats participating in training programs of short-duration (10-20 min) and low intensity had higher life expectancies (Retzlaff et al. 1966, Edington et al. 1972).

According to the WHO (2002), 'exclusive breastfeeding is defined as no other food or drink, not even water, for 6 months of life'. Exclusive and prolonged breastfeeding has been associated with protection against long-term chronic diseases such as obesity and diabetes (Harder et al. 2005). However, only $35 \%$ of infants worldwide are exclusively breastfed during the first 4 months of life (WHO 2003).

Our group developed two experimental models for early weaning. In the first model, we used a pharmacological approach to inhibit the production of maternal prolactin (PRL) with the dopamine agonist bromo$\alpha$-ergocryptine (Bro). This method programs for obesity, hyperleptinemia, leptin resistance (Bonomo et al. 2007), and hypothyroidism (Bonomo et al. 2008), and symptoms (including insulin resistance and an altered lipid profile) are similar to those of metabolic syndrome (Moura et al. 2009). More recently, we obtained a similar profile in adult animals with a non-pharmacological model where a maternal bandage was used to cover the teats of the dam in the late lactation, thus also inducing an early weaning of offspring (Lima et al. 2011, 2013).

Using a well-established model of hypothalamic obesity in rodents (neonatal treatment with monosodium L-glutamate), Scomparin et al. (2006) observed significant decreases in fat mass with a low-intensity swimming training program of $15 \mathrm{~min} /$ day, 3 days a week. This result indicated that short-duration low-intensity training programs could be an interesting way of promoting physical activity. In addition, moderate physical training attenuates the effects of a low-protein maternal diet during lactation on the expression of leptin in the visceral adipose tissue of the adult offspring (de Melo Montenegro et al. 2012). Thus, the aim of this study was to investigate the effects of short-duration low-intensity chronic exercise on adult rats born to dams subjected to an inhibition of the production of PRL during the last 3 days of lactation (which is equivalent to an early weaning of 1 month in a human). Additionally, we evaluated parameters, such as fat mass, lipid profile, glycogen levels, and glucose homeostasis, that might be affected by exercise. These parameters were shown to be affected by this experimental model of early weaning and could be reverted or prevented by low-intensity moderate exercise.

\section{Materials and methods}

The study protocol was approved by the Ethics Committee of the Biology, Institute of State, University of Rio de Janeiro, Brazil (CEA/186/2007 based on the principles promulgated by Brazilian law no. 11.794/2008 (Marques et al. 2009)). Wistar rats at 120 days of age were kept at $25 \pm 1{ }^{\circ} \mathrm{C}$ on a dark-light cycle $(0700-1900 \mathrm{~h})$. Adult virgin female rats were caged with male rats at a proportion of 3:1. During pregnancy and lactation, dams were housed in individual cages and provided with water ad libitum and a standard pellet diet. After birth, all litters were adjusted to six males for each dam to maximize lactational performance. Generally, pregnant rats produce 10-12 pups. Only mothers with a litter size of ten were used to avoid the influence of the litter size on the programming effect.

\section{Model of programming for maternal hypoprolactinemia during late lactation}

Lactating rats were separated into two groups. The control group ( $\mathrm{C}, n=30)$ received a saline treatment for the last 3 days of lactation $(19,20$, and 21 days) and the treated group (Bro, $n=30$ ) received $1 \mathrm{mg}$ Bro (Novartis) twice a day for the same period (last 3 days of lactation). After weaning, two pups were randomly selected from each litter. These pups received the saline or Bro treatment

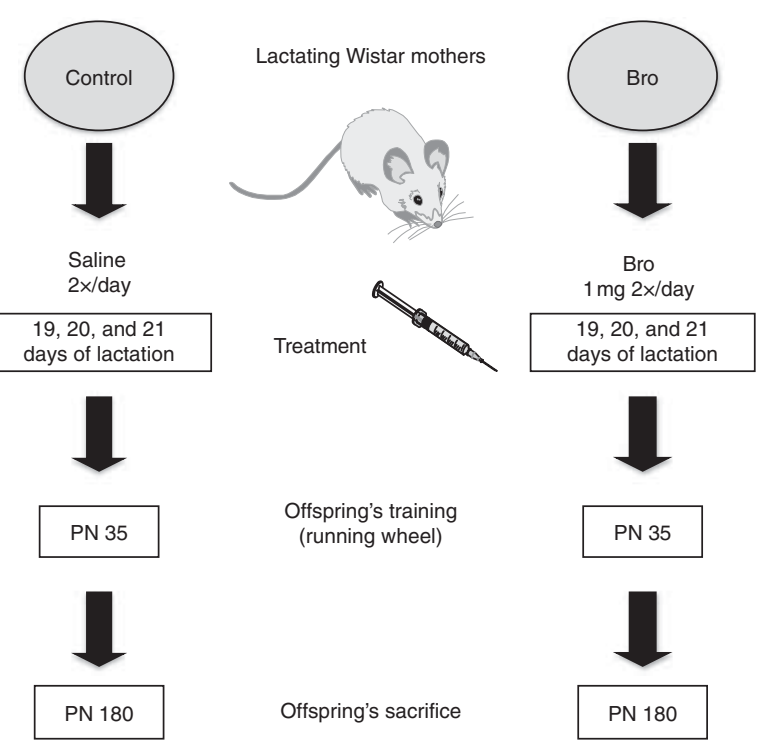

Figure 1

Pharmacological early weaning model: programming for maternal hypoprolactinemia during late lactation.

Published by Bioscientifica Ltd 
during lactation, resulting in the following experimental groups: the sedentary control group (C-Sed, $n=10$ ), maintained in a sedentary condition during the experiment; the control group subjected to exercise training on a running wheel (C-Ex, $n=10)$; the treated sedentary group (Bro-Sed, $n=11$ ); and the treated exercising group (Bro-Ex, $n=10$ ) (Fig. 1).

\section{Running exercise training program}

At 35 days of age, each rat was made to run until 180 days of age; the training lasted $15 \mathrm{~min}$ and was performed 5 days a week. The mean velocity of the treadmill was set at $17 \mathrm{~m} / \mathrm{min}$ for all experimental periods, as this intensity is considered low and represents a level of oxygen consumption below $50-60 \%$ of the maximum oxygen uptake $\left(\mathrm{VO}_{2}\right.$ max; Brooks \& White 1978). Additionally, this speed is slightly above the walk-trot gait transition (Lynn et al. 1998) and thus does not constitute an exhaustive training load. Preliminary acclimation was not necessary, as all animals were able to run for $15 \mathrm{~min}$ without exhaustion in the first attempt after water stimulation was applied. The training protocol was performed on a motorized running wheel (model EP 172, Insight, São Paulo, Brazil), and additional exercise parameters (volume and duration) were based on previous work of Scomparin et al. (2006). To stimulate continuous running behavior, we used a water flux with a controlled temperature $\left(32 \pm 2{ }^{\circ} \mathrm{C}\right)$ positioned at the rear end of the running wheel. A recipient positioned below the running wheel provided the water, and an aquarium pump generated the flux with a flow capacity of $300 \mathrm{l} / \mathrm{h}$.

\section{Body weight and food intake}

The body weight was evaluated from 35 days of age until 180 days of age. Food intake was monitored every 2 days until killing and was calculated according to the equation:

$\mathrm{F}=\frac{(\mathrm{IQ}-\mathrm{FQ}) / d}{n}$

where F, food intake; IQ, initial quantity; FQ, final quantity; $n$, number of animals in cage; and $d$, number of days between measurements.

\section{Physical capacity}

At 180 days of age, the last training session consisted of a non-exhaustive physical test to evaluate the exercise capacity of all animals. Forty-eight hours before killing, the rats were subjected to an acute bout of training consisting of running for $15 \mathrm{~min}$ at the same velocity as during training $(17 \mathrm{~m} / \mathrm{min})$.

\section{Anesthesia and killing procedures}

Forty-eight hours after the physical capacity evaluation, all offspring were killed with a lethal dose of thiopental sodium (400 mg/kg, i.p.). This interval was chosen to avoid any residual effects of acute exercise. Blood samples were obtained by cardiac puncture, centrifuged to obtain plasma $\left(2000 \boldsymbol{g}\right.$ at $4{ }^{\circ} \mathrm{C}$ for $\left.15 \mathrm{~min}\right)$, and kept at $-20^{\circ} \mathrm{C}$ until subsequent analysis. The skeletal muscle (soleus and extensor digitorum longus (EDL)) and liver were excised and kept frozen $\left(-80^{\circ} \mathrm{C}\right)$. The visceral fat mass (VFM) was dissected out and weighed to evaluate the central adiposity.

\section{Tissue glycogen content}

This measurement follows the procedure reported previously (Casimiro-Lopes et al. 2008) and is briefly detailed here. The soleus and EDL muscles were weighed and homogenized in a Turrax dispersing machine (IKA, Wilmington, NC, USA) with $1 \mathrm{ml}$ buffer $(50 \mathrm{~mol} / \mathrm{l}$ Tris-HCl; $5 \mathrm{~mol} / \mathrm{l} \mathrm{NaF}, 5 \mathrm{~mol} / \mathrm{l}$ EGTA, and $1 \mathrm{~mol} / \mathrm{l}$ dithiothreitol, $\mathrm{pH}$ 7.2). After centrifugation (2000 $\boldsymbol{g}$ at $4{ }^{\circ} \mathrm{C}$ for $20 \mathrm{~min}$ ), $600 \mu \mathrm{l}$ supernatant were removed and frozen. Subsequently, $100 \mu$ l supernatant were incubated with $2 \mathrm{U}$ amyloglucosidase (Sigma A7420) and suspended in $0.2 \mathrm{M}$ sodium acetate at $\mathrm{pH} 4.8$ in a final volume of $200 \mu \mathrm{l}$ for $4 \mathrm{~h}$ at $40^{\circ} \mathrm{C}$. The liver was weighed and homogenized with $4 \mathrm{ml}$ trichloroacetic acid (TCA) $10 \%$ $(\mathrm{w} / \mathrm{v})$. After centrifugation $\left(1000 \boldsymbol{g}\right.$ at $4{ }^{\circ} \mathrm{C}$ for $\left.10 \mathrm{~min}\right)$, $2 \mathrm{ml}$ supernatant were added to $5 \mathrm{ml}$ of absolute ethanol and frozen. After $24 \mathrm{~h}$, the mixture was centrifuged (1000 at $4{ }^{\circ} \mathrm{C}$ for $10 \mathrm{~min}$ ) and the supernatant was discarded. Glycogen was hydrolyzed by boiling the pellet for $30 \mathrm{~min}$ with $\mathrm{HCl}(1 \mathrm{M})$. To neutralize the mixture, $1 \mathrm{ml} \mathrm{NaOH}(1 \mathrm{M})$ was added. For both assays, a standard curve with increasing concentrations of glycogen was constructed using the same experimental conditions. The glucose produced by muscle and liver glycogen hydrolysis was measured using a commercial kit (Glucox, Doles, Goiás, Brazil). To ensure that the glucose originated only from glycogen, blanks without enzyme were processed and subtracted from the experimental samples. The values were expressed as milligrams per liter per gram.

Published by Bioscientifica Ltd 


\section{Measurement of blood hormones and glycemia}

Hormone levels were determined by a single RIA. The total tri-iodothyronine $\left(\mathrm{T}_{3}\right)$ and thyroxine $\left(\mathrm{T}_{4}\right)$ levels were determined using a commercial RIA Kit (ICN Pharmaceuticals, Inc., New York, NY, USA), as described by Moura et al. (1987), with assay sensitivities of $25 \mathrm{ng} / \mathrm{ml}$ and $2 \mu \mathrm{g} / \mathrm{dl}$ and intra-assay coefficients of variation $(\mathrm{CV})$ of 3.8 and $4 \%$ respectively. Insulin levels were measured with a commercial RIA Kit (ICN Biomedicals, Inc., Aurora, OH, USA) with an assay sensitivity of $0.1 \mathrm{ng} / \mathrm{ml}$ and an intra-assay $\mathrm{CV}$ of $4.2 \%$. The corticosteronemia was evaluated using a commercial kit for rats (ImmuChem 125 I, double antibody, ICN Biomedicals, Inc., Costa Mesa, CA, USA) with an assay sensitivity of $7.7 \mathrm{ng} / \mathrm{ml}$ and an intra-assay $\mathrm{CV}$ of $7.1 \%$. Glycemia was determined in blood samples from the tail vein of fasting rats using a glucometer (Accu-Chek Advantage; Roche Diagnostics). Glucose homeostasis was evaluated using the insulin resistance index (IRI), the product of the fasting insulin level $(\mu \mathrm{IU} / \mathrm{ml})$, and the fasting glucose level (mol/l), as proposed by Ahrén \& Scheurink (1998).

\section{Blood lipid profile}

Total cholesterol, HDL cholesterol (HDL-c), and triglycerides were evaluated using commercial kits (Bioclin, Belo Horizonte, Minas Gerais, Brazil). LDL cholesterol (LDL-c) and very LDL-c (VLDL-c) were calculated with the Friedewald equation (Friedewald et al. 1972). The data were expressed as milligrams per deciliter. The atherogenicity indices Castelli I and II were calculated with the equation proposed by Castelli (1984).

\section{Plasma cell injury}

Cell damage was estimated by plasma lactate dehydrogenase (LDH) activity, which was evaluated with a commercial kit (Doles). The data were expressed as international units per liter.

\section{Statistical analysis}

The normality of the distribution of each data set was evaluated using the Kolmogorov-Smirnov test. The body mass and food intake were analyzed using twoway ANOVA followed by a Bonferroni's post-test. The other parameters were analyzed using one-way ANOVA with the Newman-Keuls post-test. The data are presented as the mean \pm s.e.m., with the level of significance set at $P<0.05$. All analyses were performed using GraphPad Prism 5 Software (GraphPad Software, Inc., La Jolla, CA, USA).
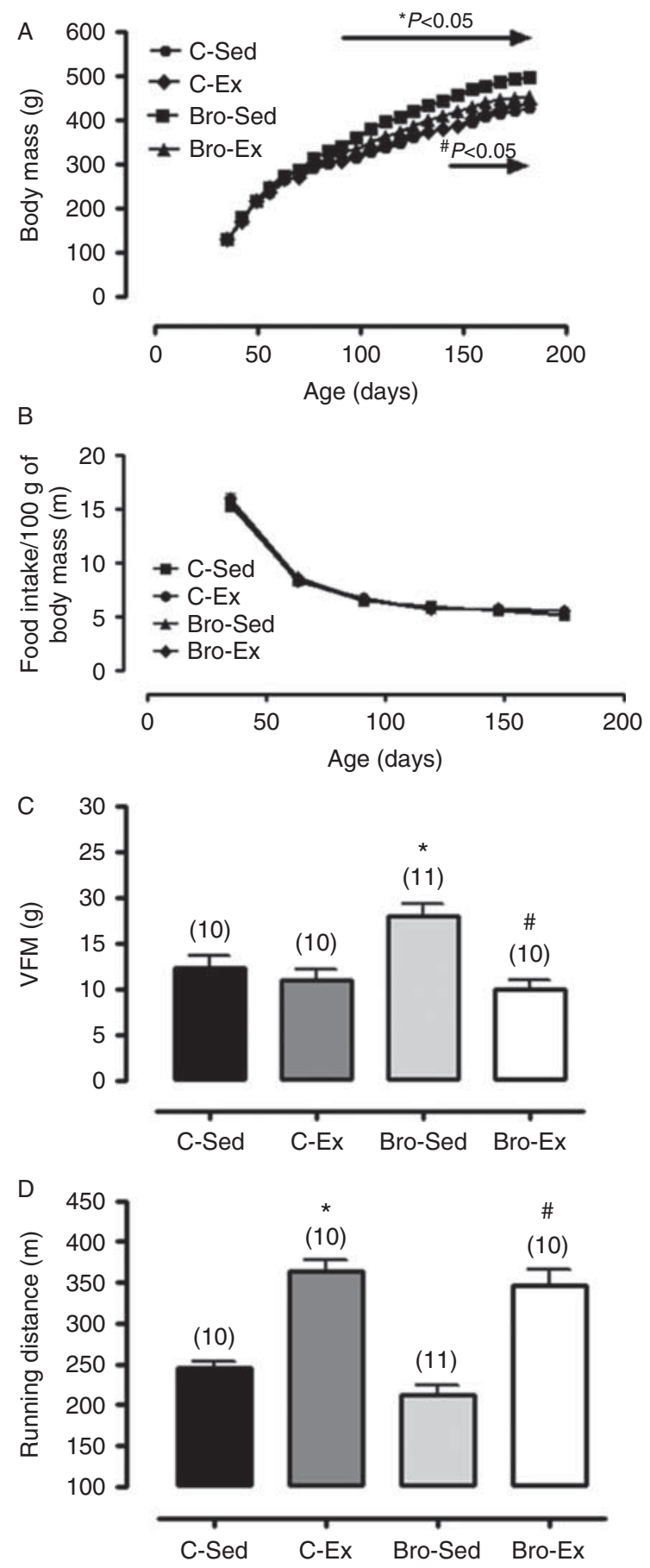

Figure 2

Body mass (A), food intake (B), VFM (C), and running distance (D) in sedentary and trained adult offspring of Bro or saline-treated animals. The number of animals used is between parentheses. * vs C-Sed and $\#$ vs Bro-Sed $(P<0.05)$.

Published by Bioscientifica Ltd. 
Table 1 Lipid profile in sedentary and trained adult offspring of Bro or saline-treated animals. Values are given as mean \pm S.E.M.

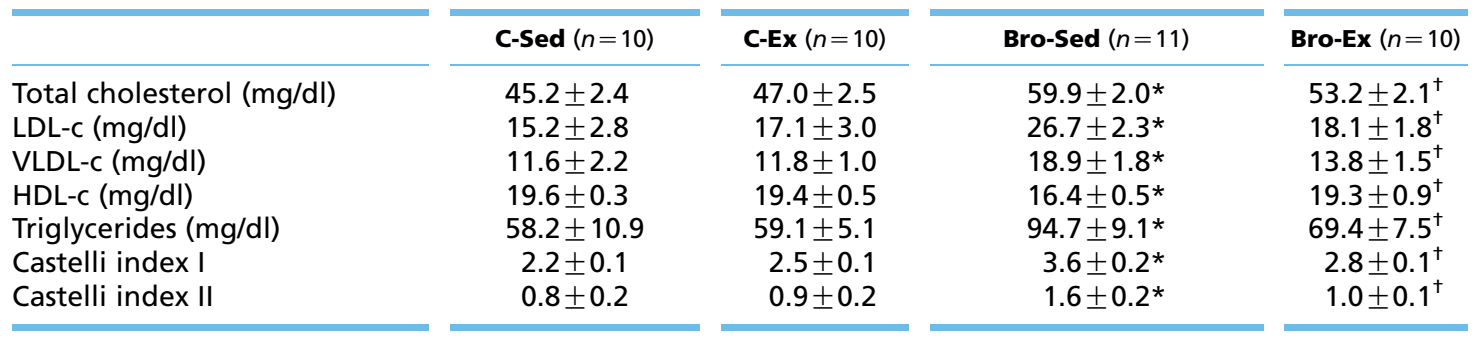

HDL-C, HDL cholesterol; LDL-C, LDL cholesterol; VLDL-C, very LDL cholesterol. * vs C-Sed and † vs Bro-Sed $(P<0.05)$.

\section{Results}

Body mass values were higher in animals of the Bro-Sed group than in animals of the C-Sed group at 98 days of age; the animals in the Bro-Ex group had lower values of body mass at 147 days of age than those in the Bro-Sed group. All these alterations persisted throughout the entire experiment. No significant differences were observed between the animals of the C-Ex group and those of the C-Sed group. The food intake did not significantly differ among any groups during the experimental period. At 180 days, the VFM was higher in the Bro-Sed animals than in the C-Sed $(+46 \%)$ and Bro-Ex animals. As expected, the maximum running distance for $15 \mathrm{~min}$ was higher in the trained animals than in the control animals (C-Ex, $+49 \%$ and Bro-Ex, $+63 \%)$. The sedentary offspring ran similar distances (Fig. 2).

Table 1 shows the lipid profile and atherogenicity indices in the offspring subjected to the experimental conditions. The rats in the Bro-Sed group had higher levels of total cholesterol $(+32 \%)$, VLDL-c $(+63 \%)$, LDL-c $(+76 \%)$, and triglycerides $(+63 \%)$ and lower levels of HDL-c $(-16 \%)$ than the animals in the C-Sed group. The lipid profile was not altered in the C-Ex animals, but the Bro-Ex group had lower levels of total cholesterol (-11\%), LDL-c $(-32 \%)$, VLDL-c $(-26 \%)$, and triglycerides $(-27 \%)$ than those in the Bro-Sed group. This profile was also similar to those observed in the C-Sed and C-Ex animals. Consequently, the Bro-Sed animals had higher Castelli I (+61\%) and Castelli II (+101\%) indices than animals in the C-Sed group, and the Bro-Ex animals had lower levels of these indices ( -23 and $-34 \%$ respectively) than the Bro-Sed offspring.

The Bro-Sed animals had higher levels of glycemia $(+11 \%)$ but similar serum insulin levels. Blood glucose levels were lowest in the Bro-Ex offspring $(-11 \%)$; however, the serum insulin level was lower in both trained groups (C-Ex and Bro-Ex, $-22 \%$ ) than in their respective controls. As expected, the IRI was higher in the Bro-Sed group $(+25 \%)$ and lower in the trained groups (C-Ex, $-25 \%$ and Bro-Ex, $-32 \%$ ), as shown in Table 2.

The thyroid hormone levels indicated that the animals of the Bro-Sed group had experienced a hypothyroid-like behavior; the total $\mathrm{T}_{3}(-20 \%)$ and $\mathrm{T}_{4}(-19 \%)$ levels were lower in these animals than in their respective controls. Physical training stimulated higher levels of total $\mathrm{T}_{3}(+29 \%)$ in the Bro-Ex group than in the Bro-Sed group. Higher levels of serum corticosterone $(+52 \%)$ were also observed in the Bro-Sed group; these levels were attenuated by physical training in the Bro-Ex animals $(-37 \%)$, producing levels similar to those observed in the C-Sed and C-Ex animals (Table 3).

Table 4 shows the tissue glycogen levels and the effect of physical training. Hepatic glycogen was higher in the C-Ex group $(+30 \%)$ than in the C-Sed group. Chronic exercise did not influence the skeletal muscle glycogen content in any group for any muscle fiber type.

Table 2 Glucose homeostasis in sedentary and trained adult offspring of Bro- or saline-treated (control) animals. Values are given as mean \pm s.E.M.

\begin{tabular}{|c|c|c|}
\hline & C-Sed $(n=10)$ & C-Ex $(n=10)$ \\
\hline Glycemia (mg/dl) & $93.7 \pm 1.8$ & $91.9 \pm 2.5$ \\
\hline Insulin $(\mu \mathrm{IU} / \mathrm{ml})$ & $45.8 \pm 2.9$ & $35.5 \pm 1.7 *$ \\
\hline IRI & $239.3 \pm 17.3$ & $180.4 \pm 7.9$ * \\
\hline
\end{tabular}

\begin{tabular}{crrr}
\hline Bro-Sed $(n=11)$ & & Bro-Ex $(n=10)$ \\
\cline { 1 - 1 } $104.4 \pm 1.8^{*}$ & & $92.6 \pm 3.6^{\dagger}$ \\
$51.6 \pm 3.7$ & & $40.4 \pm 2.2^{\dagger}$ \\
$300.4 \pm 24.7^{*}$ & & $205.2 \pm 9.3^{\dagger}$ \\
\hline
\end{tabular}

IRI, insulin resistance index. * vs C-Sed and † vs Bro-Sed $(P<0.05)$.

http://joe.endocrinology-journals.org DOI: $10.1530 / \mathrm{JOE}-13-0102$
๑) 2013 Society for Endocrinology Printed in Great Britain
Published by Bioscientifica Ltd 
Table 3 Thyroid hormones and corticosterone in sedentary and trained adult offspring of Broor saline-treated (control) animals. Values are given as mean \pm s.E.M.

\begin{tabular}{|c|c|c|c|c|}
\hline & C-Sed $(n=10)$ & C-Ex $(n=10)$ & Bro-Sed $(n=11)$ & Bro-Ex $(n=10)$ \\
\hline Total $T_{3}(n g / d l)$ & $59.2 \pm 3.0$ & $54.7 \pm 2.6$ & $47.4 \pm 2.4^{*}$ & $60.9 \pm 3.1^{\dagger}$ \\
\hline Total $\mathrm{T}_{4}(\mu \mathrm{g} / \mathrm{dl})$ & $1.2 \pm 0.1$ & $1.1 \pm 0.1$ & $0.9 \pm 0.05$ * & $1.1 \pm 0.04$ \\
\hline Corticosterone (ng/ml) & $252.6 \pm 19.5$ & $244.1 \pm 18.7$ & $384.1 \pm 38.2 *$ & $242.7 \pm 12.4^{\dagger}$ \\
\hline
\end{tabular}

Physical training on the motorized running wheel promoted higher levels of LDH in the Bro-Ex animals than in the C-Sed $(+57 \%)$ and Bro-Sed $(+85 \%)$ animals, as shown in Fig. 3.

\section{Discussion}

Our results show that the Bro-Sed offspring had symptoms of metabolic syndrome, including visceral obesity, hypertriglyceridemia, lower HDL-c, hypertension, and insulin resistance, as similar results previously reported by our laboratory (Bonomo et al. 2007, Moura et al. 2009). Physical training consisting of low-intensity short-duration chronic exercise on motorized running wheels induced higher fitness levels in regular rats (C-Ex group). The absence of adaptive alterations in other parameters such as the lipid profile and corticosterone and thyroid hormone levels could be due to training load parameters that were not sufficient to stimulate beneficial responses in normal animals. However, glucose homeostasis significantly improved both in terms of the insulin sensitivity and the liver glycogen levels.

Low-intensity short-duration physical training in Bro-Ex animals normalized most parameters of visceral obesity, lipid profile, and glucose homeostasis. Similar modifications in fat mass were described previously (Dantas et al. 2010) in animals exposed to overfeeding after treadmill training for $60 \mathrm{~min} /$ day, 5 days a week. Scomparin et al. (2006) reported that mice that were previously treated with monosodium glutamate (MSG) during the neonatal period had lower levels of visceral fat after shorter sessions of swimming training ( $15 \mathrm{~min} /$ day, 3 days a week), suggesting that the beneficial effects of chronic exercise could be achieved with lower training parameters.

Early weaning changes serum leptin levels in weaned animals (Bonomo et al. 2005, Lima et al. 2011). This early change in the leptin level is critical for establishing neural circuitry in the hypothalamus (Bouret et al. 2004) at a different set point of regulation. The inhibition of the production of maternal PRL may cause obesity in progeny via this mechanism; consequently, the inhibition of the production of PRL may impair the physical capacity of the progeny, as this inhibition is associated with other metabolic and hormonal alterations (such as changes in leptin levels and insulin resistance). Furthermore, the inhibition of the production of maternal PRL at the end of lactation induces a hypothyroidism in 180-day-old adult offspring (Bonomo et al. 2008) that is related to low physical capacity (Zarzeczny et al. 1996, Casimiro-Lopes et al. 2008). However, previous work from our laboratory showed that animals in this model had higher exercise capacity at 90 days; this capacity returned to control levels at 180 days, even in animals with higher levels of VFM during both periods. These results appear to be mediated by higher liver glycogen levels in young animals that normalized with increasing age (Casimiro-Lopes et al. 2012). Thus, the alterations in leptin, insulin actions, and thyroid hormonal status may have contributed to lower glycogen liver accumulation when the Bro animals grew older.

The total $\mathrm{T}_{3}$ levels, which were lower in the Bro-Sed group, reached values similar to those observed in the C-Sed and C-Ex groups, indicating a normalization effect of chronic exercise. The change in $\mathrm{T}_{3}$ levels appears to be more pronounced than that of the $\mathrm{T}_{4}$ levels, suggesting

Table 4 Glycogen content in muscle (EDL and soleus) and liver in sedentary and trained adult offspring of Bro- or saline-treated (control) animals. Values are given as mean \pm s.E.M.

\begin{tabular}{|c|c|c|c|c|}
\hline & C-Sed $(n=10)$ & C-EXX $(n=10)$ & Bro-Sed $(n=11)$ & Bro-Ex $(n=10)$ \\
\hline Soleus glycogen $(\mathrm{mg} / \mathrm{ml}$ per $\mathrm{g})$ & $0.3 \pm 0.02$ & $0.4 \pm 0.04$ & $0.3 \pm 0.02$ & $0.4 \pm 0.03$ \\
\hline EDL glycogen $(\mathrm{mg} / \mathrm{ml}$ per $\mathrm{g})$ & $0.4 \pm 0.08$ & $0.5 \pm 0.08$ & $0.4 \pm 0.06$ & $0.6 \pm 0.10$ \\
\hline Liver glycogen $(\mathrm{mg} / \mathrm{ml}$ per $\mathrm{g})$ & $15.9 \pm 2.0$ & $20.7 \pm 0.9 *$ & $17.4 \pm 0.5$ & $19.0 \pm 0.9$ \\
\hline
\end{tabular}

http://joe.endocrinology-journals.org DOI: $10.1530 / J O E-13-0102$
() 2013 Society for Endocrinology Printed in Great Britain
Published by Bioscientifica Ltd 


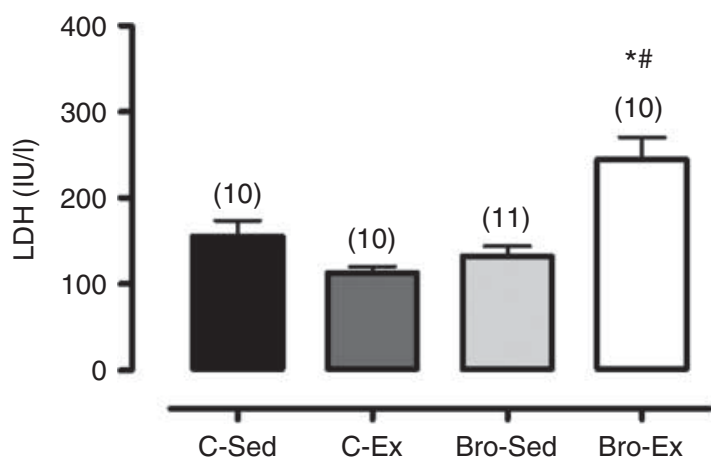

Figure 3

Plasma levels of LDH in sedentary and trained adult offspring of Bro or saline-treated animals. The number of animals used is between parentheses. * vs C-Sed and \# vs Bro-Sed $(P<0.05)$.

a higher component of low $\mathrm{T}_{3}$ syndrome due to lower peripheral deiodination of $\mathrm{T}_{4}$ to $\mathrm{T}_{3}$. Corticosterone is known to decrease liver deiodinase (Aceves et al. 2003, Araujo et al. 2009), and the corticosterone levels were higher in the animals of the Bro-Sed group; exercise appeared to normalize corticosteronemia in these animals. An acute bout of exercise appears to influence thyroid hormone concentrations (Fortunato et al. 2008, CasimiroLopes et al. 2012), a finding that was also observed in chronically exercised mice (Katzeff et al. 1988). In our study, the C-Ex rats did not show any alterations in thyroid hormone concentrations. Ciloglu et al. (2005) observed that the thyroid hormone response depends on the exercise intensity (i.e. heart rate percentage). In this case, the absence of response in the control rats could be related to the low intensity of the training program.

Corticosterone levels were not affected by physical training in the C-Ex group; however, the Bro-Ex animals had lower levels of corticosterone than those of the BroSed group, suggesting a lowering effect mediated by chronic exercise. Starzec et al. (1983) observed that chronically stressed rats had lower levels of corticosterone when physically trained. Some studies suggest that exercise could reduce circulating ACTH levels or promote a higher threshold for adrenal gland stimulation by ACTH (Tharp \& Buuck 1974, Wittert et al. 1996).

Interestingly, the lipid profile was completely normalized in the Bro-Ex offspring, further demonstrating the effect of running wheel training. This result was previously observed in other studies with different training modalities (Burneiko et al. 2004, Guerra et al. 2007).

Physical training did not significantly change the glucose levels in the C-Ex group; however, both the insulin and IRI levels were influenced by chronic exercise.
The same pattern was observed in the Bro-Ex offspring when compared with the animals of the Bro-Sed group. These results could be explained by the glucose-lowering effects of exercise through increased GLUT4 expression in skeletal muscle, leading to higher insulin sensitivity (James et al. 1985, Terada et al. 2001). This higher insulin sensitivity also explains the higher liver glycogen concentration in the C-Ex group. However, this change was not observed in the Bro-Ex group, possibly contributing to a worse prognosis for these animals and higher LDH levels.

Higher physical capacity is a normal adaptation to chronic exercise that was observed in both trained groups. Interestingly, the skeletal muscle glycogen levels were not affected by training in any group, though liver glycogen levels were higher in the C-Ex animals. Additionally, none of the deleterious features of the inhibition of the production of maternal PRL affected the running capacity of the Bro offspring. Tissue depots of glycogen are generally of fundamental importance to exercise performance in humans (Tsintzas \& Williams 1998) and rats (Slentz et al. 1990). Specifically, in rats, skeletal muscle glycogen is not a factor that determines exercise capacity. Pederson et al. (2005) observed that physical capacity for strenuous or endurance exercise was not significantly affected in mice lacking the Gys1 gene, which encodes the muscle isoform of glycogen synthase. Additionally, skeletal muscle glycogen is not mobilized during low-intensity exercise in rats (Baldwin et al. 1973, Raja et al. 2003); however, liver glycogen is strongly mobilized during exercise, independent of the intensity of the exercise (Gleeson \& Waring 1986). Thus, these studies indicate that the short-duration low-intensity training elicited by the running wheel could stimulate glycogen supercompensation in C-Ex animals but not in Bro-Ex animals. These conflicting results suggest that the training parameters for Bro-Ex offspring could be inadequate. This deficiency is possibly caused by a lowered threshold for exercise recuperation, as the elevated training volume and/or intensity could interfere with glycogen compensation in rats (Ghanbari-Niaki et al. 2010).

Blood levels of LDH are related to tissue damage to cell membranes, leading to leakage of cell constituents (Dawson et al. 2002). This feature is also closely related to exercise intensity (Loegering 1974, Ramos et al. 2013); however, these results are not observed in the C-Ex offspring indicating raised cellular stress resistance (Jeong et al. 2012). Higher levels of plasma LDH in the Bro-Ex rats suggest an impaired capacity of cell membrane adaptation to chronic exercise load besides other positive responses in adiposity, lipid profile, thyroid status, and insulin sensitivity. Deleterious adaptations

Published by Bioscientifica Ltd. 
from excessive/inadequate training were reported by Moraska et al. (2000) and included the following: thymic involution, adrenal hypertrophy, and impaired immune function. Interestingly, other responses such as lower body mass and higher citrate synthase activity were also detected.

This paper demonstrates a novel model of metabolic syndrome caused by early weaning in which hypothyroidism may explain changes in the lipid profile, visceral adiposity, and glucose homeostasis; these changes are partially or totally restored by low-intensity exercise. However, some alterations persist and can compromise the future physical capacity of these programmed animals.

In summary, short-duration long-term running wheel training could counterbalance the characteristics of metabolic syndrome and the hypothyroid profile observed in animals subjected to maternal PRL inhibition. However, higher plasma LDH levels suggest that these animals appear to be more sensitive to training than previously thought. These results suggest that programmed animals in this experimental model can achieve substantial benefits from chronic exercise but could have a lower threshold for exercise response than control rats. Less frequent training sessions could offer a possible way to induce positive exercise adaptations in Bro-Ex offspring.

\section{Declaration of interest}

The authors declare that there is no conflict of interest that could be perceived as prejudicing the impartiality of the research reported.

\section{Funding}

This research was supported by National Council for Scientific and Technological Development (Conselho Nacional de Desenvolvimento Científico e Tecnológico (CNPq)), Coordination for the Enhancement of Higher Education Personnel (Coordenação de Aperfeiçoamento de Pessoal de Nível Superior (CAPES)), and State of Rio de Janeiro Carlos Chagas Filho Research Foundation (Fundação Carlos Chagas Filho de Amparo à Pesquisa do Estado do Rio de Janeiro (FAPERJ)). G B was recipient of a CNPq fellowship.

\section{Acknowledgements}

The authors thank Ms Mônica Moura and Mr Ulisses Siqueira for technical assistance.

\section{References}

Aceves C, Escobar C, Rojas-Huidobro R, Vázquez-Martínez O, Martínez-Merlos T, Aguilar-Roblero R \& Díaz-Muñoz M 2003 Liver 5 -deiodinase activity is modified in rats under restricted feeding schedules: evidence for post-translational regulation. Journal of Endocrinology 179 91-96. (doi:10.1677/joe.0.1790091)
Ahrén B \& Scheurink AJ 1998 Marked hyperleptinemia after high-fat diet associated with severe glucose intolerance in mice. European Journal of Endocrinology 139 461-467. (doi:10.1530/eje.0.1390461)

Araujo RL, Andrade BM, da Silva ML, Ferreira AC \& Carvalho DP 2009 Tissue-specific deiodinase regulation during food restriction and low replacement dose of leptin in rats. American Journal of Physiology. Endocrinology and Metabolism 296 1157-1163. (doi:10.1152/ajpendo. 90869.2008)

Baldwin KM, Fitts RH, Booth FW, Winder WW \& Holloszy JO 1973 Depletion of muscle and liver glycogen during exercise. Pflügers Archiv: European Journal of Physiology 354 203-212. (doi:10.1007/BF00584644)

Beaglehole R \& Yach D 2003 Globalisation and the prevention and control of non-communicable disease: the neglected chronic diseases of adults. Lancet 362 903-908. (doi:10.1016/S0140-6736(03)14335-8)

Bonomo IT, Lisboa PC, Passos MC, Pazos-Moura CC, Reis AM \& Egberto EG 2005 Prolaction inhibition in lactanting rats changes leptin transfer through the milk. Hormone and Metabolic Research 37 220-225. (doi:10.1055/s-2005-861381)

Bonomo IT, Lisboa PC, Pereira AR, Passos MC \& Moura EG 2007 Prolactin inhibition in dams during lactation programs for overweight and leptin resistance in adult offspring. Journal of Endocrinology 192 339-344. (doi:10.1677/joe.1.06952)

Bonomo IT, Lisboa PC, Passos MC, Alves SB, Reis AM \& Moura EG 2008 Prolactin inhibition at the end of lactation programs for a central hypothyroidism in adult rat. Journal of Endocrinology 198 331-337. (doi:10.1677/JOE-07-0505)

Bosello O \& Zamboni M 2000 Visceral obesity and metabolic syndrome. Obesity Reviews 1 47-56. (doi:10.1046/j.1467-789x.2000.00008.x)

Bouret SG, Draper SJ \& Simerly RB 2004 Trophic action of leptin on hypothalamic neurons that regulate feeding. Science 304 108-110. (doi:10.1126/science.1095004)

Brooks GA \& White TP 1978 Determination of metabolic and heart rate responses of rats to treadmill exercise. Journal of Applied Physiology 45 1009-1015.

Burneiko RC, Diniz YS, Faine LA, Galhardi CM, Padovani CB, Novelli EL \& Cicogna AC 2004 Impact of the training program on lipid profile and cardiac health. Biological Research 37 53-59. (doi:10.4067/S071697602004000100006)

Casimiro-Lopes G, Alves SB, Salerno VP, Passos MC, Lisboa PC \& Moura EG 2008 Maximum acute exercise tolerance in hyperthyroid and hypothyroid rats subjected to forced swimming. Hormone and Metabolic Research 40 276-280. (doi:10.1055/s-2008-1046799)

Casimiro-Lopes G, Lisboa PC, Koury JC, Boaventura G, Passos MC \& Moura EG 2012 Maternal prolactin inhibition during lactation affects physical performance evaluated by acute exhaustive swimming exercise in adult rat offspring. Hormone and Metabolic Research 44 123-129. (doi:10.1055/s-0031-1299711)

Castelli WP 1984 Epidemiology of coronary heart disease: the Framingham Study. American Journal of Medicine 76 4-12. (doi:10.1016/00029343(84)90952-5)

Ciloglu F, Peker F, Pehlivan A, Karacabey K, İlhan N, Saygin O \& Ozmerdivenli R 2005 Exercise intensity and its effects on thyroid hormones. Neuro Endocrinology Letters 26 830-834.

Dantas EM, Pimentel EB, Gonçalves CP, Lunz W, Rodrigues SL \& Mill JG 2010 Effects of chronic treadmill training on body mass gain and visceral fat accumulation in overfed rats. Brazilian Journal of Medical and Biological Research 43 515-521. (doi:10.1590/S0100879X2010000500014)

Dawson R, Biasetti M, Messina S \& Dominy J 2002 The cytoprotective role of taurine in exercise-induced muscle injury. Amino Acids 22 309-324. (doi:10.1007/s007260200017)

Edington DW, Cosmas AC \& Mccafferty WB 1972 Exercise and longevity: evidence for a threshold age. Journal of Gerontology 27 341-343. (doi:10.1093/geronj/27.3.341)

Fortunato RS, Ignácio DL, Padron AS, Peçanha R, Marassi MP, Rosenthal D, Werneck-de-Castro JP \& Carvalho DP 2008 The effect of acute exercise 
session on thyroid hormone economy in rats. Journal of Endocrinology 198 347-353. (doi:10.1677/JOE-08-0174)

Friedewald WT, Levy RI \& Fredrickson DS 1972 Estimation of the concentration of low-density lipoprotein cholesterol in plasma, without use of the preparative ultracentrifuge. Clinical Chemistry 18 499-502.

Garber CE, Blissmer B, Deschenes MR, Franklin BA, Lamonte MJ, Lee IM, Nieman DC \& Swain DP 2011 American college of sports medicine position stand. Quantity and quality of exercise for developing and maintaining cardiorespiratory, musculoskeletal, and neuromotor fitness in apparently healthy adults: guidance for prescribing exercise. Medicine and Science in Sports and Exercise 43 1334-1359. (doi:10.1249/ MSS.0b013e318213fefb)

Ghanbari-Niaki A, Farshidi Z \& Fathi R 2010 Effect of different endurance training intensities on resting levels of skeletal muscle and liver glycogen concentrations in male rats. International Journal of Endocrinology and Metabolism 8 79-81.

Gleeson M \& Waring J 1986 Influence of diet on the storage, mobilization and utilization of energy reserves in trained and untrained rats. Comparative Biochemistry and Physiology 85 411-415. (doi:10.1016/ 0300-9629(86)90422-6)

Guerra RL, Prado WL, Cheik NC, Viana FP, Botero JP, Vendramini RC, Carlos IZ, Rossi EA \& Damaso AR 2007 Effects of 2 or 5 consecutive exercise days on adipocyte area and lipid parameters in Wistar rats. Lipids in Health and Disease 6 1-16. (doi:10.1186/1476-511X-6-16)

Harder T, Bergmann R, Kallischnigg G \& Plagem A 2005 Duration of breastfeeding and risk of overweight: a meta-analysis. American Journal of Epidemiology 162 397-403. (doi:10.1093/aje/kwi222)

James DE, Kraegen EW \& Chisholm DJ 1985 Effects of exercise training on in vivo insulin action in individual tissues of the rat. Journal of Clinical Investigation 76 657-666. (doi:10.1172/JCI112019)

Jeong HW, Cho SY, Kim S, Shin ES, Kim JM, Song MJ, Park PJ, Sohn JH, Park H, Seo D et al. 2012 Chitooligosaccharide induces mitochondrial biogenesis and increases exercise endurance through the activation of Sirt1 and AMPK in rats. PLOS ONE 7 e40073. (doi:10.1371/journal. pone.0040073)

Katzeff HL, Bovbjerg D \& Mark DA 1988 Exercise regulation of triiodothyronine metabolism. American Journal of Physiology. Endocrinology and Metabolism 255 824-828.

Lima N, da S, de Moura EG, Passos MC, Nogueira Neto FJ, Reis AM, de Oliveira E \& Lisboa PC 2011 Early weaning causes undernutrition for a short period and programmes some metabolic syndrome components and leptin resistance in adult rat offspring. British Journal of Nutrition 105 1405-1413. (doi:10.1017/S0007114510005064)

Lima NS, Moura EG, Franco JG, Pinheiro CR, Pazos-Moura CC, Cabanelas A, Carlos AS, Nascimento-Saba CC, de Oliveira E \& Lisboa PC 2013 Developmental plasticity of endocrine disorders in obesity model primide by early weaning in dams. Hormone and Metabolic Research 45 22-30. (doi:10.1055/s-0032-1323703)

Loegering DJ 1974 Effect of swimming and treadmill exercise on plasma enzyme levels in rats. Experimental Biology and Medicine 147 177-180. (doi:10.3181/00379727-147-38307)

Lynn R, Talbot JA \& Morgan DL 1998 Differences in rat skeletal muscles after incline and decline running. Journal of Applied Physiology 85 98-104.

Marques RG, Morales MM \& Petroianu A 2009 Brazilian law for scientific use of animals. Acta Cirúrgica Brasileira 24 69-74. (doi:10.1590/S010286502009000100015)

Masuzaki H, Paterson J, Shinyama H, Morton NM, Mullins JJ, Seckl JR \& Flier JS 2001 A transgenic model of visceral obesity and the metabolic syndrome. Science 294 2166-2170. (doi:10.1126/science.1066285)

de Mélo Montenegro IH, Moita L, Dos Reis FK, de Oliveira E, Lisboa PC, de Moura EG, Manhães-de-Castro R \& Leandro CG 2012 Effects of a moderate physical training on the leptin synthesis by adipose tissue of adult rats submitted to a perinatal low-protein diet. Hormone and Metabolic Research 44 814-818. (doi:10.1055/s-0032-1316350)

Moraska A, Deak T, Spencer RL, Roth D \& Fleshner M 2000 Treadmill running produces both positive and negative physiological adaptations in Sprague-Dawley rats. American Journal of Physiology. Regulatory, Integrative and Comparative Physiology 279 1321-1329.

Moura EG, Ramos CF, Nascimento CC, Rosenthal D \& Breitenbach MM 1987 Thyroid function in fasting rats: variations in ${ }^{131}$ I uptake and transient decrease of peroxidase activity. Brazilian Journal of Medical and Biological Research 20 407-410.

Moura EG, Bonomo IT, Nogueira-Neto JF, Oliveira E, Trevenzoli IH, Reis AM, Passos MC \& Lisboa PC 2009 Maternal prolactin inhibition during lactation programs for metabolic syndrome in adult progeny. Journal of Physiology 587 4919-4929. (doi:10.1113/jphysiol.2009.176289)

Pederson BA, Cope CR, Schroeder JM, Smith MW, Irimia JM, Thurberg BL, DePaoli-Roach AA \& Roach PJ 2005 Exercise capacity of mice genetically lacking muscle glycogen synthase: in mice, muscle glycogen is not essential for exercise. Journal of Biological Chemistry $\mathbf{2 8 0}$ 17260-17265. (doi:10.1074/jbc.M410448200)

Raja G, Bräu1 L, Palmer TN \& Fournier PA 2003 Repeated bouts of highintensity exercise and muscle glycogen sparing in the rat. Journal of Experimental Biology 206 2159-2166. (doi:10.1242/jeb.00416)

Ramos D, Martins EG, Viana-Gomes D, Casimiro-Lopes G \& Salerno VP 2013 Biomarkers of oxidative stress and tissue damage released by muscle and liver after a single bout of swimming exercise. Applied Physiology, Nutrition, and Metabolism 38 507-511. (doi:10.1139/ apnm-2012-0302)

Retzlaff E, Fontaine J \& Furuta W 1966 Effect of daily exercise on life-span of albino rats. Geriatrics 21 171-177.

Scomparin DX, Grassiolli S, Marçal AC, Gravena C, Andreazzi AE \& Mathias PC 2006 Swim training applied at early age is critical to adrenal medulla catecholamine content and to attenuate monosodium L-glutamate-obesity onset in mice. Life Sciences 79 2151-2156. (doi:10.1016/j.lfs.2006.07.012)

Slentz CA, Davis JM, Settles DL, Pate RR \& Settles SJ 1990 Glucose feedings and exercise in rats: glycogen use, hormone responses, and performance. Journal of Applied Physiology 69 989-994.

Starzec JJ, Berger DF \& Hesse R 1983 Effects of stress and exercise on plasma corticosterone, plasma cholesterol, and aortic cholesterol levels in rats. Psychosomatic Medicine 45 219-226.

Terada S, Yokozeki T, Kawanaka K, Ogawa K, Higuchi M, Ezaki O \& Tabata I 2001 Effects of high-intensity swimming training on GLUT-4 and glucose transport activity in rat skeletal muscle. Journal of Applied Physiology 90 2019-2024.

Tharp GD \& Buuck JR 1974 Adrenal adaptation to chronic exercise. Journal of Applied Physiology 37 720-722.

Tsintzas K \& Williams C 1998 Human muscle glycogen metabolism during exercise. Effect of carbohydrate supplementation. Sports Medicine $\mathbf{2 5}$ 7-23. (doi:10.2165/00007256-199825010-00002)

WHO 2002 The optimal duration of exclusive breastfeeding. Geneva, Switzerland: World Health Organization.

WHO 2003 Global strategy for infant and young child feeding. Geneva, Switzerland: World Health Organization.

Wittert GA, Livesey JH, Espiner EA \& Donald RA 1996 Adaptation of the hypothalamopituitary adrenal axis to chronic exercise stress in humans. Medicine and Science in Sports and Exercise 28 1015-1019. (doi:10.1097/00005768-199608000-00011)

Zarzeczny R, Pilis W, Langfort J, Kaciuba-Uscilko H \& Nazar K 1996 Influence of thyroid hormones on exercise tolerance and lactate threshold in rats. Journal of Physiology and Pharmacology 47 503-513.

Received in final form 17 June 2013

Accepted 17 July 2013

Accepted Preprint published online 21 June 2013 